OPEN ACCESS

Edited by:

Thierry M. L. B. Vander Borght,

Catholic University of Louvain,

Belgium

Reviewed by:

Ramin Sadeghi,

Mashhad University of Medical

Sciences, Iran

Serge Goldman,

Free University of Brussels, Belgium

*Correspondence:

Sylvie Chalon

sylvie.chalon@univ-tours.fr

Specialty section:

This article was submitted to

Nuclear Medicine,

a section of the journal

Frontiers in Medicine

Received: 25 February 2019 Accepted: 10 April 2019

Published: 03 May 2019

Citation:

Chalon S, Vercouillie J, Payoux P, Deloye J-B, Malherbe C, Le Jeune F, Arlicot N, Salabert A-S, Guilloteau D, Emond P and Ribeiro M-J (2019) The

Story of the Dopamine Transporter

PET Tracer LBT-999: From

Conception to Clinical Use.

Front. Med. 6:90.

doi: 10.3389/fmed.2019.00090

\section{The Story of the Dopamine Transporter PET Tracer LBT-999: From Conception to Clinical Use}

\author{
Sylvie Chalon ${ }^{1 *}$, Johnny Vercouillie ${ }^{1,2}$, Pierre Payoux ${ }^{3,4}$, Jean-Bernard Deloye ${ }^{5}$, \\ Cécile Malherbe ${ }^{1}$, Florence Le Jeune ${ }^{6,7}$, Nicolas Arlicot ${ }^{1,2,8}$, Anne-Sophie Salabert ${ }^{3,4}$, \\ Denis Guilloteau ${ }^{1,8}$, Patrick Emond ${ }^{1,8}$ and Maria-Joao Ribeiro ${ }^{1,2,8}$ \\ ${ }^{1}$ UMR 1253, iBrain, Université de Tours, Inserm, Tours, France, ${ }^{2}$ Inserm CIC 1415, University Hospital, Tours, France, \\ ${ }^{3}$ ToNIC, Toulouse Neurolmaging Center, Université de Toulouse, Inserm, UPS, Toulouse, France, ${ }^{4}$ University Hospital, \\ Nuclear Medicine Unit, Toulouse, France, ${ }^{5}$ Zionexa, 42 avenue de la Grande Armée, Paris, France, ${ }^{6}$ University of Rennes 1 , \\ Rennes, France, ${ }^{7}$ Department of Nuclear Medicine, Centre Eugène Marquis, Rennes, France, ${ }^{8}$ CHRU Tours, Tours, France
}

The membrane dopamine transporter (DAT) is involved in a number of brain disorders and its exploration by positron emission tomography (PET) imaging is highly relevant for the early and differential diagnosis, follow-up and treatment assessment of these diseases. A number of carbon-11 and fluor-18 labeled tracers are to date available for this aim, the majority of them being derived from the chemical structure of cocaine. The development of such a tracer, from its conception to its use, is a long process, the expected result being to obtain the best radiopharmaceutical adapted for clinical protocols. In this context, the cocaine derivative (E)- $N$-(4-fluorobut-2-enyl)2 $\beta$-carbomethoxy-3 $\beta$-(4'-tolyl)nortropane, or LBT-999, has passed all the required stages of the development that makes it now a highly relevant imaging tool, particularly in the context of Parkinson's disease. This review describes the different steps of the development of LBT-999 which initially came from its non-fluorinated derivative (E)-N-(3-iodoprop-2-enyl)-2-carbomethoxy-3-(4-methylphenyl) nortropane, or $\mathrm{PE} 2 \mathrm{l}$, because of its high promising properties. $\left[{ }^{18} \mathrm{~F}\right.$ LBT-999 has been extensively characterized in rodent and non-human primate models, in which it demonstrated its capability to explore in vivo the DAT localized at the dopaminergic nerve endings as well as at the mesencephalic cell bodies, in physiological conditions. In lesion-induced rat models of Parkinson's disease, $\left[{ }^{18} \mathrm{~F}\right] \mathrm{LBT}-999$ was able to precisely quantify in vivo the dopaminergic neuron loss, and to assess the beneficial effects of therapeutic approaches such as pharmacological treatment and cell transplantation. Finally recent clinical data demonstrated the efficiency of $\left[{ }^{18} \mathrm{~F}\right.$ LBT-999 in the diagnosis of Parkinson's disease.

Keywords: PET, dopaminergic neuron, Parkinson's disease, radiopharmaceutical, basal ganglia

\section{IN VIVO IMAGING OF THE DAT: A HIGHLY POTENT TOOL FOR BRAIN DISORDERS}

The dopaminergic neurotransmission is strongly involved in the regulation of multiple brain functions such as locomotion, cognition and reward, and then plays a major role in a great number of brain disorders such as Parkinson's disease (PD) (1) but also several neuropsychiatric disorders (2). In this context, in vivo exploration of this system through molecular imaging methods is a 
real added value for the diagnosis, follow-up, and treatment of such disorders. Several molecular targets of the dopaminergic neurotransmission can be explored in vivo, at both the preand post-synaptic level. These explorations require the use of specific radiotracers able to bind specifically to each target and then to quantify it as accurately as possible. For this aim a high number of tracers have been developed, either labeled with $\gamma$ emitters such as ${ }^{123} \mathrm{I}$ or ${ }^{99} \mathrm{~m}$ Tc for single photon emission tomography (SPECT), or with $\beta+$ emitters such as ${ }^{11} \mathrm{C}$ or ${ }^{18} \mathrm{~F}$ for positron emission tomography (PET). Several tracers are yet available for the different types of postsynaptic dopaminergic receptors (3). Regarding pre-synaptic dopaminergic neurons, SPECT and/or PET exploration of three main molecular targets are to date available. The 6-[ $\left.{ }^{18} \mathrm{~F}\right]$-fluoroL-dopa or $\left[{ }^{18} \mathrm{~F}\right] \mathrm{DOPA}$ uptake, which reflects both the conversion of Dopa into dopamine (DA) and the storage of DA into synaptic vesicles, has been the first gold standard tool (4). Besides, the vesicular monoamine transporter 2 (VMAT2) and the membrane dopamine transporter (DAT) can also be explored. The respective advantages and drawbacks related to imaging these different pre-synaptic molecular targets have mainly been compared in the context of $\mathrm{PD}$, and prominent conclusions are summarized in Table 1.
For a long time, the DAT has been identified as a target of choice because its localization makes it a marker of neuron integrity and density, and also because it is a key-actor in the regulation of synaptic dopamine levels (13). A high number of SPECT and PET tracers have been developed for DAT imaging. In all cases, they were derived from known ligands of the DAT, and most of them from the tropane structure characteristic of cocaine (14). The first of these tracers which demonstrated its potency in the field of PD using SPECT imaging was the $2 \beta$-carbomethoxy$3 \beta$-(4-iodophenyl)tropane ( $\beta$-CIT) (15), which bound to the DAT with a high affinity (around $3 \mathrm{nM}$ ) and accumulated significantly in dopaminergic brain areas when labeled with iodine-123. Although $\beta$-CIT demonstrated its usefulness for the detection of DAT loss in PD, it had several drawbacks such as a similar affinity for the dopamine and serotonin transporters (16), a poor signal/noise ratio and an in vivo kinetics requiring as long as $24 \mathrm{~h}$ to reach equilibrium state allowing the DAT quantification in the striatum (17).

A number of new $\beta$-CIT derivatives were then proposed to overcome these weaknesses. Among them, the N-(3-iodopro- $2 E$ enyl)- $2 \beta$-carbomethoxy-3 $\beta$-(4-methylphenyl)nortropane (PE2I) is structurally characterized by the presence of a methyl group on the phenyl ring of the $\beta$-CIT structure instead of an iodine, and

TABLE 1 | Presynaptic molecular PET imaging targets of the dopaminergic neurotransmission.

\begin{tabular}{|c|c|c|c|c|}
\hline Molecular target & Examples of tracer & Advantages & Drawbacks & References \\
\hline DOPA decarboxylase & {$\left[{ }^{18} \mathrm{~F}\right] \mathrm{F}-\mathrm{DOPA}$} & $\begin{array}{l}\text { - Distinguishes patients with advanced PD } \\
\text { from patients with de novo PD }\end{array}$ & $\begin{array}{l}\text { - Reflects both the conversion of Dopa into DA } \\
\text { and pre-synaptic storage of DA } \\
\text { - Possible under-estimation of DA neurons } \\
\text { loss in de novo PD patients due to an } \\
\text { up-regulation of DA synthesis }\end{array}$ & $(5-7)$ \\
\hline $\begin{array}{l}\text { Vesicular monoamine } \\
\text { transporter } 2 \text { (VMAT2) }\end{array}$ & $\begin{array}{l}{\left[{ }^{11} \mathrm{C}\right] \mathrm{DTBZ}} \\
{\left[{ }^{18} \mathrm{~F}\right] \mathrm{AV}-133}\end{array}$ & $\begin{array}{l}\text { - Detects early PD vs. healthy controls } \\
\text { - Improves diagnostic accuracy in clinically } \\
\quad \text { uncertain parkinsonian syndrome }\end{array}$ & - Present on all monoaminergic neurons & $(8-10)$ \\
\hline $\begin{array}{l}\text { Membrane dopamine } \\
\text { transporter (DAT) }\end{array}$ & $\begin{array}{l}{\left[{ }^{18} \mathrm{~F}\right] \mathrm{FP}-\mathrm{CIT}} \\
{\left[{ }^{11} \mathrm{C}\right] \mathrm{PE} 2 \mathrm{I}} \\
{\left[{ }^{18} \mathrm{~F}\right] \mathrm{FE}-\mathrm{PE} 2 \mathrm{I}}\end{array}$ & $\begin{array}{l}\text { - Distinguishes patients with advanced PD } \\
\text { from patients with de novo PD } \\
\text { - Greater sensitivity than F-DOPA for detecting } \\
\text { motor severity in PD } \\
\text { - Identification of patients at risks for } \\
\text { developing PSP or FTD }\end{array}$ & $\begin{array}{l}\text { - Possible over-estimation of DA neurons loss } \\
\text { due to a down-regulation of the DAT }\end{array}$ & $(5,11,12)$ \\
\hline
\end{tabular}

AV-133, fluoropropyldihydrotetrabenazine; DA, dopamine; F-DOPA, 6-fluoro-dopa; DTBZ, dihydrotetrabenazine, FDT, frontotemporal dementia; PSP, progressive supranuclear palsy.

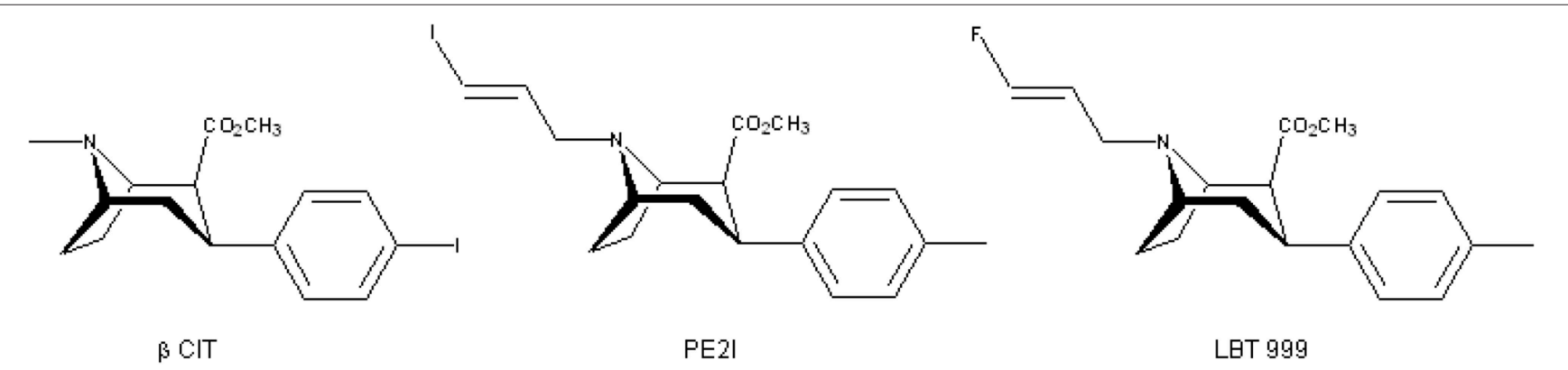

FIGURE 1 | Chemical structures of $\beta$-CIT, PE2I, and LBT-999. 
a 3-iodopro-2E-enyl group at the tropane nitrogen instead of a methyl carried by $\beta$-CIT (18). These chemical modifications have led to a significant improvement in the pharmacological profile of this ligand $(19,20)$, showing a high selectivity for the DAT toward the serotonin transporter (SERT). The high affinity and selectivity made PE2I a highly potent tracer to image the DAT in vivo either by SPECT when labeled with ${ }^{123}$ I and by PET when labeled with ${ }^{11} \mathrm{C}$. In this context, $\left[{ }^{123} \mathrm{I}\right] \mathrm{PE} 2 \mathrm{I}$ demonstrated its usefulness for the differential diagnosis between patients suffering from PD and atypical parkinsonian syndromes without degeneration of striatal dopaminergic nerve endings (21). The PET imaging with $\left[{ }^{11} \mathrm{C}\right]$ PE2I has also been successfully used in this same disease $(11,22)$ but also in schizophrenia $(23,24)$, attention deficit / hyperactivity disorders (25) and more recently in the exploration of the reward dopaminergic pathway (26).

\section{DEVELOPMENT OF LBT-999}

Regarding the high potency of binding of PE2I for the DAT and because PET imaging enables in vivo exploration at high resolution and high sensitivity, we developed the fluorinated derivative of PE2I, i.e., 8-((E)-4-fluoro-but-2-enyl)-3 $\beta$-p-tolyl-8aza-bicyclo[3.2.1] octane-2 $\beta$-carboxylic acid methyl ester (LBT999) (Figure 1).

The in vitro pharmacological evaluation of LBT-999 demonstrated that its properties was close to that of PE2I, with a good affinity for the DAT $(9 \mathrm{nM})$ and a $\mathrm{Ki}>1 \mu \mathrm{M}$ for different ligands of the serotonin and norepinephrine transporters (27). Firstly, LBT-999 was labeled with carbon-11 (28) by methylation of the acid precursor that can be obtained in an easier way compared to a precursor useable for fluorine labeling. The $\left[{ }^{11}\right.$ C]LBT-999 shown to have a high in vivo accumulation in brain areas containing high levels of DAT both in rats and

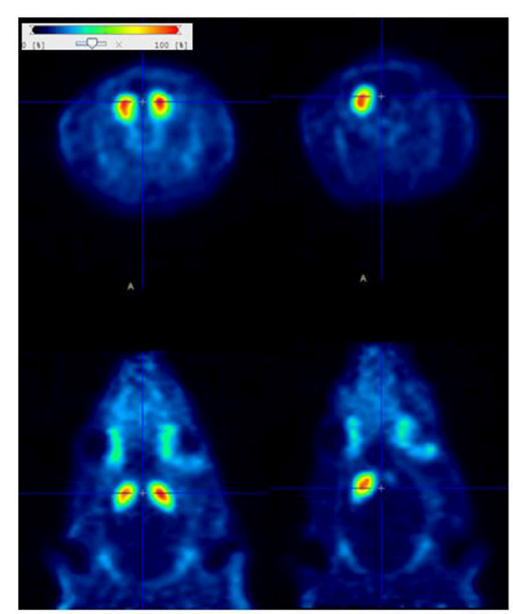

FIGURE 2 | Coronal (upper side) and axial (lower side) PET static images (30-50 min post-injection) obtained with [ $\left.{ }^{18} \mathrm{~F}\right]$ LBT-999 in a normal rat (left) and in a rat lesioned with $6-\mathrm{OHDA}$ in the right striatum. The quantitative analysis revealed a decreased of $70 \%$ in the tracer accumulation in the lesioned vs. intact striatum. monkeys $(27,28)$. Based on these results, the development of the radiolabeling with $\left[{ }^{18} \mathrm{~F}\right]$ was then realized, first using a two-step methodology (29) followed by a one-step approach (30) required for rapid and reproducible radiofluorination dedicated to preclinical and clinical studies. As for the $\left[{ }^{11} \mathrm{C}\right] \mathrm{LBT}$ 999, $\left[{ }^{18} \mathrm{~F}\right] \mathrm{LBT}-999$ rapidly, and highly entered the rat brain where its distribution was in agreement with the DAT density. Importantly, $1 \mathrm{~h}$ post-injection, the in vivo specific binding represented by the ratio of accumulation in the striatum to cerebellum, was 10 times higher for LBT-999 (ratio of 25) (27) compared to that we obtained previously with PE2I in same experimental conditions (31). For LBT as for PE2I, the striatal accumulation at $1 \mathrm{~h}$ post-injection was around $70 \%$ decreased in the presence of a saturating dose of the DAT inhibitor GBR12909, whereas no significant effect was observed with a pre-injection of paroxetine (SERT ligand) or nisoxetine (NET ligand). In monkey, LBT-999 was also able to bind specifically to the DAT, either labeled with $\left[{ }^{11} \mathrm{C}\right](27)$ or with $\left[{ }^{18} \mathrm{~F}\right]$ (32). This last study demonstrated that LBT was also suitable for DAT exploration in extra-striatal regions, and that the estimated dosimetry was acceptable for human use.

\section{PRECLINICAL EXPERIMENTS IN ANIMAL MODELS}

As the final aim of the development of a new PET tracer is its use for human health improvement, it is of high value to explore the properties of such a candidate tracer in animal models of human diseases. For this purpose, we performed in a first step in rats, an extensive test-retest study that demonstrated the ability of $\left[{ }^{18} \mathrm{~F}\right]$ LBT-999 to quantify the DAT with high reproducibility (variability of $8-14 \%$ ) and reliability (intra-class correlation coefficient, ICC, of 0.9 ) in the striatum, whereas these parameters were less accurate in the substantia nigra, in relation with the small size of this brain structure (33). In a rat model of early PD induced by a moderate unilateral striatal lesion using 6hydroxydopamine (6-OHDA), we showed that $\left[{ }^{18} \mathrm{~F}\right] \mathrm{LBT}-999$ was

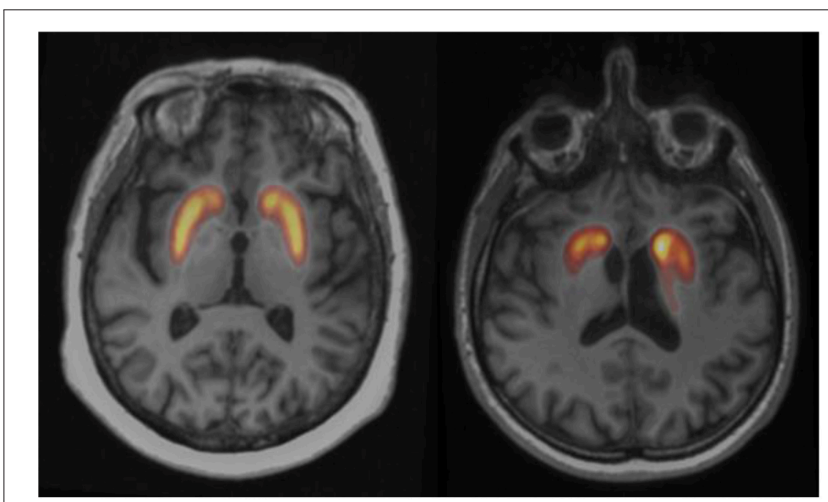

FIGURE 3 | Fusion axial slices between PET and MRI of the $\left[{ }^{18} \mathrm{~F}\right.$ LBT-999 uptake at the level of the striatum in a control subject (left) and a drug-naiive patient with early Parkinson disease (right). The radiopharmaceutical uptake is asymmetrically decreased in Parkinson patient. 
able to accurately quantify in vivo the dopaminergic endings loss (Figure 2), in full agreement with the results obtained by in vitro autoradiography with $\left[{ }^{125} \mathrm{I}\right] \mathrm{PE} 2 \mathrm{I}$ on brain sections (34).

It was also important to assess the potency of $\left[{ }^{18} \mathrm{~F}\right] \mathrm{LBT}-999$ to evaluate the efficacy of various therapeutic approaches aiming at the preservation or replacement of dopaminergic neurons in vivo in the rat model of 6-OHDA lesions. This property was demonstrated in the case of a pharmacological therapeutic approach (35) as well as for the graft of human embryonic stem cells-derived midbrain dopaminergic neurons (36). These whole findings provided strong preclinical support for clinical translation of $\left[{ }^{18} \mathrm{~F}\right] \mathrm{LBT}-999$.

\section{THE USE OF $\left[{ }^{18} \mathrm{~F}\right]$ LBT-999 IN HUMAN}

$\left[{ }^{18}\right.$ F]LBT-999 has recently been evaluated in clinical setting (37, 38). Preliminary results on a small sample of 6 subjects with early Parkinson's disease and 8 healthy controls demonstrated that injection of $\left[{ }^{18} \mathrm{~F}\right] \mathrm{LBT}-999$ is feasible and pharmacologically safe. $\left[{ }^{18}\right.$ F]LBT-999 distribution was consistent with DAT density in human brain and PET images in both caudate and putamen nuclei indicate that this tracer may successfully differentiate the two groups of subjects (Figure 3). On the basis of these initial findings, $\left[{ }^{18} \mathrm{~F}\right] \mathrm{LBT}-999$ might be a suitable radiopharmaceutical for PET assessment of DAT in future clinical studies.

\section{REFERENCES}

1. Meder D, Herz DM, Rowe JB, Lehéricy S, Siebner HR. The role of dopamine in the brain - lessons learned from Parkinson's disease. NeuroImage. (2018) 190:79-93. doi: 10.1016/j.neuroimage.2018.11.021

2. Thal LB, Tomlinson ID, Quinlan MA, Kovtun O, Blakely RD, Rosenthal SJ. Single quantum dot imaging reveals PKC $\beta$-dependent alterations in membrane diffusion and clustering of an attention-deficit hyperactivity disorder / autism / bipolar disorder-associated dopamine transporter variant. ACS Chem Neurosci. (2019) 10:460-71. doi: 10.1021/acschemneuro.8b00350

3. Niccolini F, Su P, Politis M. Dopamine receptor mapping with PET imaging in Parkinson's disease J Neurol. (2014) 261:225163. doi: 10.1007/s00415-014-7302-2

4. Gjegge A, Reith J, Dyve S, Leger G, Guttman M, Diksic M, et al. Dopa decarboxylase activity of the living human brain. Proc Natl Acad Sci USA. (1991) 88:2721-5.

5. Eshuis SA, Maguire RP, Leenders KL, Jonkman S, JagerPL. Comparison of FP-CIT SPECT with F-DOPA PET in patients with de novo and advanced Parkinson's disease. Eur J Nucl Med Mol Imaging. (2006) 33:2009. doi: 10.1007/s00259-005-1904-y

6. Lee CS, Samii A, Sossi V, Ruth TJ, Schulzer M, Holden JE, et al. In vivo positron emission tomographic evidence for compensatory changes in presynaptic dopaminergic nerve terminals in Parkinson's disease. Ann Neurol. (2000) 47:493-503. doi: 10.1002/1531-8249(200004)47:4<493::AIDANA13>3.0.CO;2-4

7. Ribeiro M-J, Vidailhet M, Loc'h C, Dupel C, Nguyen J-P, Ponchant M, et al. Dopaminergic function and dopamine transporter binding assessed with positron emission tomography in Parkinson disease. Arch Neurol. (2002) 59:580-6. doi: 10.1001/archneur.59.4.580

8. Martin WR, Wieler M, Stoessl AJ, Schulzer M. Dihydrotetrabenazine positron emission tomography imaging in early, untreated Parkinson's disease. Ann Neurol. (2008) 63:388-94. doi: 10.1002/ana.21320

9. Okamura N, Villemagne VL, Drago J, Pejoska S, Dhamija RK, Mulligan RS, et al. In vivo measurement of vesicular monoamine transporter type 2

\section{CONCLUSIONS}

After the identification of a brain molecular target whose PET exploration would be crucial for improvement of the diagnosis and/or treatment of a particular disease, it is a long way to make available an optimal radiotracer. A very high number of tracers have been developed as potential DAT imaging agents, the most promising being based on the tropane scaffold derived from the structure of cocaine. Several SPECT compounds are used in clinical protocols, such as ${ }^{99 \mathrm{~m}} \mathrm{Tc}-\mathrm{TRODAT}$ (39) and [123I]FPCIT (40). However, they suffer from many disadvantages such as poor sensitivity, spatial resolution, and slow kinetic uptake, and PET ligands should be a good alternative. We described in this paper the development of one of these tracers, $\left[{ }^{18} \mathrm{~F}\right] \mathrm{LBT}$ 999, which has the particularity to be highly specific for its target, and which is now ready to be used for clinical purpose.

\section{AUTHOR CONTRIBUTIONS}

All authors listed have made a substantial, direct and intellectual contribution to the work, and approved it for publication.

\section{ACKNOWLEDGMENTS}

This work was supported by Labex IRON (ANR-11-LABX-18-01).

density in Parkinson disease with 18F-AV-133. J Nucl Med. (2010) 51:2238. doi: 10.2967/jnumed.109.070094

10. Xu SS, Alexander PK, Lie Y, Dore V, Bozinovski S, Mulligan RS, et al. Diagnostic accuracy of imaging brain vesicular monoamine transporter type 2 (VMAT2) in clinically uncertain parkinsonian syndrome (CUPS): a 3-year follow-up study in community patients. BMJ Open. (2018) 8:e25533. doi: 10.1136/bmjopen-2018-025533.

11. Li W, Lao-Kaim NP, Roussakis AA, Martín-Bastida A, Valle-Guzman N, Paul G, et al. 11C-PE2I and 18F-Dopa PET for assessing progression rate in Parkinson's: a longitudinal study. Mov Dis. (2018) 33:11727. doi: $10.1002 / \mathrm{mds} .27183$

12. Yoo HS, Chung SJ, Kim S-J, Oh JS, Kim JS, Ye BS, et al. The role of 18F-FP-CIT PET in differentiation of progressive supranuclear palsy and frontotemporal dementia in the early stage. Eur $J$ Nucl Med Mol Imaging. (2018) 45:1585-95. doi: 10.1007/s00259018-4019-y

13. Mulvihill KG. Presynaptic regulation of dopamine release: Role of the DAT and VMAT2 transporters. Neurochem Int. (2019) 122:94105. doi: $10.1016 /$ j.neuint.2018.11.004

14. Brooks DJ Molecular imaging of dopamine transporter. Aging Res Rev. (2016) 30:114-21. doi: 10.1016/j.arr.2015.12.009

15. Innis RB, Seibyl JP, Scanley BE, Laruelle M, Abi-Dargham A, Wallace E, et al. Single photon emission computed tomographic imaging demonstrates loss of striatal dopamine transporters in Parkinson disease. Proc Natl Acad Sci USA. (1993) 90: 11965-9.

16. Boja JW, Mitchell WM, Patel A, Kopajtic TA, Carroll FI, Lewin AH, et al. High-affinity binding of [125I]RTI-55 to dopamine and serotonin transporters in rat brain. Synapse. (1992) 12:27-36.

17. Laruelle M, Wallace E, Seibyl JP, Baldwin RM, Zea-Ponce Y, Zoghbi SS, et al. Graphical, kinetic, and equilibrium analyses of in vivo [123I] beta-CIT binding to dopamine transporters in healthy human subjects. J Cereb Blood Flow Metab. (1994) 14:982-94.

18. Emond P, Garreau L, Chalon S, Boazi M, Caillet M, Bricard J, et al. Synthesis and ligand binding of nortropane derivatives: $\mathrm{N}$-substituted 
$2 \beta$-Carbomethoxy-3 $\beta$-(4'-iodophenyl)nortropane and $N$-(3-Iodoprop-(2E)enyl)-2 $\beta$-carbomethoxy-3 $\beta$-( $3^{\prime}, 4^{\prime}$-disubstituted phenyl)nortropane. New high-affinity and selective compounds for the dopamine transporter. J Med Chem. (1997) 40:1366-72.

19. Chalon S, Garreau L, Emond P, Zimmer L, Vilar MP, Besnard JC, et al. Pharmacological characterization of (E)- $N$-(3-iodoprop-2-enyl)-2 $\beta$ Carbomethoxy-3 $\beta$-( $4^{\prime}$-methylphenyl)nortropane as a selective and potent inhibitor of the neuronal dopamine transporter. J Pharmacol Exp Ther. (1999) 291:648-54.

20. Emond P, Guilloteau D, Chalon S. PE2I: a radiopharmaceutical for in vivo exploration of the dopamine transporter. CNS Neurosci Ther. (2008) 14:4764. doi: 10.1111/j.1527-3458.2007.00033.x

21. Ziebell M, Andersen BB, Thomsen G, Pinborg LH, Karlsborg M, Hasselbalch SG, et al. Predictive value of dopamine SPECT imaging with $\left[{ }^{123} \mathrm{I}\right] \mathrm{PE} 2 \mathrm{I}$ in patients with subtle parkinsonian symptoms. Eur J Nucl Med Mol Imaging. (2012) 39:242-50. doi: 10.1007/s00259-011-1976-9

22. Appel L, Jonasson M, Danfors T, Nyholm D, Askmark H, Lubberink M, et al. Use of $\left[{ }^{11} \mathrm{C}\right]$ PE2I PET in differential diagnosis of Parkinsonian disorders. $J$ Nucl Med. (2015) 56:234-42. doi: 10.2967/jnumed.114.148619

23. Arakawa R, Ichimiya T, Ito $\mathrm{H}$, Takano A, Okumura M, Takahashi $\mathrm{H}$ et al. Increase in thalamic binding of $\left[{ }^{11} \mathrm{C}\right] \mathrm{PE} 2 \mathrm{I}$ in patients with schizophrenia: a positron emission tomography study of dopamine transporter. J Psychiatr Res. (2009) 43:1219-23. doi: 10.1016/j.jpsychires.2009.04.009

24. Artiges E, Leroy C, Dubol M, Prat M, Pepin A, Mabondo A et al. Striatal and extrastriatal dopamine transporter availability in schizophrenia and its clinical correlates: a voxel-based and high-resolution PET study. Schizophrenia Bull. (2017) 43:1134-42. doi: 10.1093/schbul/sbw192

25. Jucaite A, Fernell E, Halldin C, Forssberg H, Farde L. Reduced midbrain dopamine transporter binding in male adolescents with attention-deficit/hyperactivity disorder: association between striatal dopamine markers and motor hyperactivity. Biol Psychiatry. (2005) 57:229-38. doi: 10.1016/j.biopsych.2004.11.009

26. Dubol M, Trichard C, Leroy C, Sandu AL, Rahim M, Granger B, et al. Dopamine transporter and reward anticipation in a dimensional perspective: a multimodal brain imaging study. Neuropsychopharmacology. (2018) 43:8207. doi: $10.1038 /$ npp. 2017.183

27. Chalon S, Hall H, Saba W, Garreau L, Dollé F, Halldin C, et al. Pharmacological characterization of (E)-N-(4-fluorobut-2-enyl)-2beta-carbomethoxy-3beta(4'-tolyl)nortropane (LBT-999) as a highly promising fluorinated ligand for the dopamine transporter. J Pharmacol Exp Ther. (2006) 317:14752. doi: 10.1124/jpet.105.096792

28. Dollé F, Emond P, Mavel S, Dezmphel S, Hinnen F, Mincheva Z, et al. Synthesis, radiosynthesis and in vivo preliminary evaluation of $\left[{ }^{11}\right.$ C]LBT-999, a selective radioligand for the visualization of the dopamine transporter with PET. Bioorg Med Chem. (2006) 14:1115-25. doi: 10.1016/j.bmc.2005.09.035

29. Dollé F, Hinnen F, Emond P, Mavel S, Mincheva Z, Saba W, et al. Radiosynthesis of $\left[{ }^{18} \mathrm{~F}\right] \mathrm{LBT}-999$, a selective radioligand for the visualization of the dopamine transporter with PET. J. Labelled Compd Rad. (2006) 49:687-98. doi: $10.1002 /$ jlcr.1092

30. Dollé F, Helfenbein J, Hinnen F, Mavel S, Mincheva Z, Saba W, et al. One-step radiosynthesis of $\left[{ }^{18} \mathrm{~F}\right] \mathrm{LBT}-999$ : a selective radioligand for the visualization of the dopamine transporter with PET. J. Labelled Compd Rad. (2007) 50:71623. doi: $10.1002 /$ jlcr.1412

31. Guilloteau D, Emond P, Baulieu JL, Garreau L, Frangin Y, Pourcelot L, et al. Exploration of the Dopamine Transporter: in vitro and in vivo characterization of a high-affinity and high-specificity iodinated tropane Derivative (E)-N-(3-iodoprop-2-enyl)-2 $\beta$ -

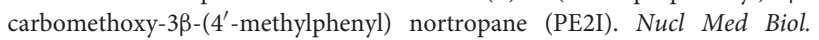
(1998) 25:331-7.

32. Varrone A, Stepanov V, Nakao R, Toth M, Gulyas B, Emond P, et al. Imaging of the striatal and extrastriatal dopamine transporter with 18F-LBT999: quantification, biodistribution, and radiation dosimetry in nonhuman primates. J Nucl Med. (2011) 52:1313-21. doi: 10.2967/jnumed.111.089953

33. Sérrière $\mathrm{S}$, Tauber $\mathrm{C}$, Vercouillie J, Guilloteau D, Deloye JB, Garreau L, et al. In vivo PET quantification of the dopamine transporter in rat brain with $\left[{ }^{18} \mathrm{~F}\right]$ LBT-999. Nucl Med Biol. (2014) 41:106-13. doi: 10.1016/j.nucmedbio.2013.09.007

34. Vetel S, Sérrière S, Vercouillie J, Vergote J, Chicheri G, Deloye JB, et al. Extensive exploration of a novel rat model of Parkinson's disease using partial 6-hydroxydopamine lesion of dopaminergic neurons suggests new therapeutic approaches. Synapse. (2018) 73:e22077. doi: 10.1002/syn. 22077

35. Sérrière $\mathrm{S}$, Doméné $\mathrm{A}$, Vercouillie J, Mothes $\mathrm{C}$, Bodard $\mathrm{S}$, Rodrigues $\mathrm{N}$, et al. Assessment of the protection of dopaminergic neurons by an alpha7 nicotinic receptor agonist, PHA 543613 using [(18)F]LBT-999 in a Parkinson's disease rat model. Front Med. (2015) 2:61. doi: 10.3389/fmed.2015.00061

36. Grealish S, Diguet E, Kirkeby A, Mattson B, Heuer A, Bramoulle Y, et al. Human ESC-derived dopamine neurons show similar preclinical efficacy and potency to fetal neurons when grafted in a rat model of Parkinson's disease. Cell Stem Cell. (2014) 15:653-65. doi: 10.1016/j.stem.2014.09.017

37. Arlicot N, Vercouillie J, Malherbe C, Bidault R, Gissot V, Maia S, et al. PET imaging of Dopamine Transporter with 18F-LBT999: first human exploration. J Nucl Med. (2017) 58:276.

38. Ribeiro MJ, Vercouillie J, Arlicot N, Mondon K, Gissot V, Maia S, et al. A simplified method for the diagnosis of striatal dopaminergic dysfunction using PET with a new fluorine DAT tracer, the 18F-LBT-999. J Nucl Med. (2017) 58:413.

39. Gupta V, Ranjan R, Verma R, Belho ES, Malik D, Mahajan H. Correlation of 99mTc-TRODAT-1 SPECT imaging findings and clinical staging of Parkinson's disease. Clin Nucl Med. (2019) 44:347-50. doi: 10.1097/RLU.0000000000002529

40. Jakobson Mo S, Axelsson J, Jonasson L, Larsson A, Ögren MJ, Ögren $\mathrm{M}$, et al. Dopamine transporter imaging with $\left[{ }^{18} \mathrm{~F}\right] \mathrm{FE}-\mathrm{PE} 2 \mathrm{I}$ PET and $\left[{ }^{123} \mathrm{I}\right] \mathrm{FP}-\mathrm{CIT}$ SPECT-a clinical comparison. EJNMMI Res. (2018) 8:100. doi: $10.1186 / \mathrm{s} 13550-018-0450-0$

Conflict of Interest Statement: J-BD was employed by company Zionexa, Paris, France.

The remaining authors declare that the research was conducted in the absence of any commercial or financial relationships that could be construed as a potential conflict of interest.

Copyright (๑) 2019 Chalon, Vercouillie, Payoux, Deloye, Malherbe, Le Jeune, Arlicot, Salabert, Guilloteau, Emond and Ribeiro. This is an open-access article distributed under the terms of the Creative Commons Attribution License (CC BY). The use, distribution or reproduction in other forums is permitted, provided the original author(s) and the copyright owner(s) are credited and that the original publication in this journal is cited, in accordance with accepted academic practice. No use, distribution or reproduction is permitted which does not comply with these terms. 